\title{
Herco Steyn
}

and

\section{Rinelle Evans}

University of Pretoria

\section{Textese and secondary school learners' formal written English: Is the media hype about language decay justified?}

\begin{abstract}
This article investigates whether the media hype about the supposedly detrimental effect of textese on teenagers' formal English skills is justified. It is posited that this younger generation has reached the 'point of saturation' because they are so accustomed to seeing textisms in informal writing contexts and will therefore struggle to identify them in a formal writing context. A postpositivist research philosophy was assumed coupled with a quantitative research design. A purposefully designed proofreading protocol allowed for the collection of empirical data from South
\end{abstract}

African secondary school learners with English first-language proficiency from the upper-middle class socio-economic sphere in the Pretoria metropolis. The results indicate that the 288 respondents did not struggle to identify textisms implying that the target population had a sufficiently precise grasp of register to discredit media claims that textese is akin to language decay.

Key terms: point of saturation, register, SMS, Standard English, textese, texting 


\section{Introduction}

Textese, also called 'textspeak', 'txtese', 'chatspeak', 'txt', 'txtspk', 'txtk', 'txto', 'texting language', 'netspeak', 'Internet speak', 'txt lingo', 'SMSish', 'txtslang', 'txting' or 'txt talk', is the writing convention of shortening words so that the maximum amount of information may be conveyed in the shortest possible time and at the lowest cost, as mobile phone users pay for each 160 character text message sent (Kemp 2010:53). Due to the limitations of space and time, communicators try to maximise expressivity of words, phrases and sentences without compromising comprehensibility (Bodomo 2009:113, Balakrishnan \& Yeow 2008, Hård af Segerstad 2005: 40-46). While messaging platforms such as BlackBerry Messenger and WhatsApp have radically lowered the cost of texting, the time constraints remain. Using textisms to save time is therefore still the norm (Wood, Kemp \& Plester 2014:99). Moreover, although the widespread use of textese was largely driven by the introduction of cellular technology as a natural, intuitive response to a technological problem (Crystal 2008b), and while textese previously referred predominantly to the writing conventions used when typing a short message (SMS), in this paper we use the term to denote the linguistic phenomenon of shortening and amending words by any intelligible means possible to share a written message in the shortest amount of time, crammed into the smallest possible space, irrespective of the medium or platform through which it is used. In our inquiry 'textese' implied English textese specifically unless explicitly stated otherwise.

In this regard, Thurlow's (2006) critical discourse analysis of media accounts of computer-mediated discourse (which includes textese) reveals an overwhelmingly negative portrayal of this e-medium and indicates that textese use is equated with declining morality and literacy. There is, accordingly, a global concern that textese could affect formal written Standard English negatively and that many people, educators included, believe that textese is destroying Standard English and secondary school learners' ability to write 'properly' (Nadeem, Mohsin \& Ali 2012:1234, Hamzah, Ghorbani \& Abdullah 2009:546, O'Connor 2005:2). This has resulted in recent research considering how knowledge and use of textisms might be related to 'traditional' literacy skills (Wood et al. 2014:283). The debate as to whether or not textese has an impact on secondary school learners' formal written English is therefore an ongoing one.

\section{The portrayal of textese in the international and South African media}

An example of textese frequently being portrayed as 'misspellings' in the media (Wood, Meachem, Bowyer, Jackson, Tarczynski-Bowles and Plester 2011:432), is the publishing of a thirteen year-old Scottish schoolgirl's essay, which had been written entirely in textese ("Text Message Essay Baffles British Teacher", 2003). The textese version of the essay reads as follows: 
My smmr hols wr CWOT. B4, we used 2go2 NY 2C our bro, his GF \& thr 3 :-@ kids FTF. ILNY, it's a gr8 plc.

Translated into Standard English, the following was intended:

My summer holidays were a complete waste of time. Before, we used to go to New York to see our brother, his girlfriend and their three screaming kids face to face. I love New York. It's a great place.

Supporters of the decay theory such as John Humphrys (2007) pounced on it; presenting it as irrefutable proof that textese was tantamount to language decay. In a newspaper article entitled "I h8 txt msgs: how texting is wrecking our language", Humphrys (2007) asserts that people who use textese are "doing to our language what Genghis Khan did to his neighbours eight hundred years ago. They are destroying it: pillaging our punctuation; savaging our sentences; raping our vocabulary". Presumably the 'they' targeted by Humphrys is predominantly the digital native generation of texters. Even celebrities, most notably actor Sir Ralph Fiennes, have joined the chorus blaming textese for reducing the richness of the English language to "a world of truncated sentences, soundbites and Twitter" (Jones, 2011).

The popular perception created in the media is therefore that textese spelling conventions are detrimental to spelling and writing performance, with articles by Prigg (2012), Cooke (2012), Thomas (2012), Campbell (2008), the Associated Press (2007), Barker (2007), Uthus (2007), Bolowana (2005) and Sutherland (2002), all claiming that the use of textisms is negatively associated with secondary school learners' spelling and writing ability in their respective countries. In his article entitled "How texting made history but ruined our language - and plenty of marriages", Thomas (2012) generalises that "texts have changed the way we write, obliterating conventional punctuations and replacing properly spelled words with abbreviations, initials and 'emoticon' smiley symbols." Cooke's article (2012), entitled "SMS SOS!" asserts that "politicians have blamed the abbreviated language on the demise of literacy among the youth as punctuation, grammar and capitalisation are largely ignored in favour of brevity". Conversely, two articles published within months of each other by the same newspaper, the Daily Mail, entitled "OMG! Txts make u gd at writing? Srsly? How 'text speak' can help pupils write essays" (Edwards, 2012) and "OMG: Researchers say text messaging really is leading to a generation with poor grammar skills" (Prigg, 2012), completely contradict each other regarding the impact of textese on British secondary school learners' spelling and writing ability.

Turning to the South African context, Angela Bolowana's (2005) article entitled "R 2day's teens eroding English?" states that textese is cause for concern among English teachers and academics alike, and quotes an English lecturer from a local tertiary institution who expressed concern that due to South African secondary school learners' textese use, the quality and level of their English are deteriorating. 
Eric Uthus (2007), in his article "Text messages ruining our language", "knew the end was near" when he first received a text message containing textese, viewing English as having necessarily deteriorated since the introduction of cellular technology and text messaging. What Uthus fails to observe, however, is the fact that while he views the change from his conception of Standard English (as predecessor of textese) to textese necessarily as decay, he does not then also judge Standard English as being the decayed form of the older form of English he referred to earlier, but rather hypocritically views this as evolution. Similarly, another article, published in The Pioneer ("SMS, Internet texts are destroying English", 2013), laments the degeneration of 'proper' English and grammar and fears that if something is not done soon, the younger generation will become completely "habituated" to textese.

In a comprehensive review of the portrayal of textese in the media, Thurlow (2006) conducted a study of more than 100 media articles to ascertain how articles published in the media portray textese. Thurlow (2006: 671-672) came to the conclusion that the perspective the media have created of textese is "decidedly negative and often exaggerated, published with little regard to the actual uses of text messaging, and often in the face of evidence to the contrary", and that textese is portrayed as representing a "decisive and dramatic break with conventional practice". However, Thurlow (2006:677) acknowledges that the most recent media articles used in his study had started to report on academic work indicating a positive effect on literacy. Nevertheless, it is fair to assume that, to the casual reader, the media remains sceptical to some extent of any report suggesting a positive correlation between textese, and spelling and writing attainment (Tagg et al., 2012:3).

In South Africa specifically, Jumo's (2011) article "SMS spelling 'makes your child look stupid" quotes the then Pan South African Language Board Chairperson, Professor Sihawukele Ngubane, as saying that learners should consider the difference between textese and academic writing: "My view is that most pupils get so accustomed to slang that it affects their academic writing. SMS language is shorter and the youth will be looking at saving money and characters.... This problem is hard to resolve because they cannot distinguish between the two." Mike Hart, the co-ordinator of Pietermaritzburg's literacy programme, is also quoted as saying declining literacy is the real stumbling block for the county's education system: "If pupils use SMS language in their academic writing it is because they have not been taught the difference about what is appropriate in different contexts."

In moving to actual empirical studies conducted in the South African context, Geertsema, Hyman and Van Deventer (2011:481) employed a qualitative research design to determine secondary school teachers' perspectives on the impact of textese on learners' written language skills regarding spelling, sentence length and punctuation. One teacher participant is quoted as saying that "Learners make use of abbreviations. This style is becoming the norm due to constant use of SMS language, especially Mxit", with the mean results indicating that teachers perceive textese as having a negative effect on learners' written English (ibid.). Making use of different categories of textese use to 
classify textese, Geertsema et al. also found that grade 8 and 9 teachers had, ordered in descending order from the perceived most problematic to the least problematic types of textisms, identified (1) non-conventional spellings ('skool' for 'school'), (2) g-clippings ('goin' for 'going'), (3) letter homophones ('b' for 'be'), (4) number homophones ('2' for 'too/two/to'), (5) acronyms and initialisms ('lol' for 'laugh out loud'), (6) shortenings ('info' for 'information'), (7) contractions ('gonna' for 'going to'), and (8) emoticons (-)/:) (2011: 481-483). The conclusion was that the use of textese would probably change academic writing into a more informal style, and that textese use was negatively influencing the written language skills of English first-language grade 8 and 9 learners' written English (2011: 481-485). However, a strong negative bias underscored Geertsema et al.'s (2011:481) study, and the view that textese was necessarily having a degenerative effect on learners' written English was assumed from the outset. The questions used in the research instrument were also decidedly negative, for example, respondents were requested to indicate the extent to which they agreed with the statement "the negative influence of SMS language on written language skills causes learners to achieve poor grades in English Home Language as a subject" (2011:481), thus underscoring the negative bias in Geertsema et al.'s inquiry.

An earlier South African study by Hyman and Van Deventer (2009:45) investigated whether teachers were of the view that textese necessarily negatively influenced grade 8 and 9 learners' written English. They employed a qualitative research design, using a questionnaire to obtain teachers' views on the frequency with which they observed textese in their learners' writing and the impact that textese use had on their learners' writing. They found that textese negatively influenced the selected South African secondary school learners' written English, identifying g-clippings and non-conventional spellings as the most problematic categories of textese use. The results concur with the later findings of Geertsema et al. (2011).

Also within the South African context, Freudenberg (2009) employing a qualitative research design, examined the impact of textese on the written schoolwork of English first- and second-language secondary school learners in order to establish how widespread textese use was among this sample, and to assess whether the formal English writing of these learners showed any evidence of textese. Questionnaire data established how often learners texted and whether they felt that texting had an effect on their formal school writing. Actual writing samples indicated whether they could identify characteristics of textese that they used when texting. Freudenberg found that the participants were, in fact, able to translate textese into Standard English and vice versa with relative ease, and frequently used textese when texting. Furthermore, findings indicated that the textisms most often produced by learners were, in descending order, spelling errors, over-punctuation and a lack of punctuation, while emoticons and slang were used infrequently (Freudenberg, 2009:42). Subsequent to Freudenberg's study, Winzker, Southwood and Huddlestone (2009:11) used her data to reveal that the respondents were avid texters and users of textese. Winzker et al. (2009:4) examined respondents' English writings for various features deviating from Standard English, and found that respondents mostly made spelling and punctuation errors. Overall textisms 
did not occur frequently. Winzker et al. (2009:13) inferred that textese had a modest negative effect on written schoolwork, but significantly that students could generally gauge when it was inappropriate to use textese.

In summary, while observers such as Crystal (2008a, 2008b) eschew the negative association with textese and despite some empirical evidence both internationally and in the South African context suggesting otherwise, the popular view still seems to be that textese is a belligerent evil that is, to use Humphrys's (2007) term, "pillaging" Standard English (Tagg et al., 2012). Given such divergent views on the topic, we approached secondary school English teachers to obtain a first-hand perspective on the potential influence of textese on secondary school learners' formal written English. The teachers' responses and how they shaped our approach to our inquiry are detailed in the following section.

\section{Rationale}

The English teachers confirmed that even though learners seemed to have become desensitised regarding the use of textisms, they did not believe learners added textisms on purpose as they knew they would be penalised for using them. This 'desensitisation' is referred to as the 'point of saturation' (Nadeem, Mohsin \& Ali, 2012:1234, Hamzah, Ghorbani \& Abdullah, 2009:546, O'Connor, 2005:2, Brown-Owens, Eason \& Lader, 2003:17, Lee, 2002:3), implying that texters no longer notice textese spelling variations as they have become so used to seeing and using them. It is then only natural that young texters might sometimes confuse some of the elements of the two different registers used for formal (academic) and informal (textese), and use features of textese in contexts where such usage is decidedly inappropriate (Brown-Owens et al., 2003:17, O'Connor, 2005:2). This inadvertent use of textese - even though learners are aware of register differences - may be attributed to saturation as well as an insufficient sensitivity to the context requiring the use of a formal register (Carrington, 2005:161, Rankin, 2010:4). Based on the point of saturation possibly already having been reached, we accordingly posited that SASSLATS ${ }^{1}$ would not have a precise grasp of register and would therefore 'struggle' to identify textisms in a formal writing context (i.e. they would therefore not be 'proficient' at identifying textisms in a formal writing context). Should this postulation hold true, it would mean that the media's portrayal of textese is accurate.

1 We coined the term 'SASSLATS' (South African secondary school learners aged thirteen to seventeen) to avoid clumsy, repetitive and wordy sentence constructions. In our inquiry 'SASSLATS' shall invariably and specifically refer to SASSLATS with English first-language proficiency from the upper-middle class socio-economic sphere in the urban Pretoria region. 
In order to quantify the opposing concepts of 'struggle' and 'proficient' in the context of our inquiry, a score of more than $50 \%$ on the research instrument indicated that learners are 'proficient' in identifying textisms in formal written English as it denotes that more textisms were corrected than overlooked. By contrast, learners were deemed to have 'struggled' to identify textisms in a formal writing context if they did not correct more than $50 \%$ of the textisms - they would then have 'missed' more textese errors than they corrected. Although the 'point of saturation' cannot be related directly to the rather narrow confines of 'struggle' or 'proficient' explained above, for the purposes of this inquiry learners were seen to have reached the point of saturation if they failed to correct less than $50 \%$ of textisms on the research instrument.

Furthermore, the formal writing context we refer to in our inquiry denotes a context requiring the use of formal written Standard English. Without getting into the debate of what exactly constitutes Standard English, it here denotes the prestige variety of English, with the opposite term being 'non-standard' (Crystal, 2008d:450). Likewise, 'Standard English' denotes the codified variety generally accepted as the 'correct' or most appropriate form of English typically used in formal settings, when writing and for educational purposes, and is contrasted with textese, which denotes non-standard English (Campbell \& Mixco, 2007:192, Trask, 2000:323). Furthermore, in order to describe a linguistic system, the researcher has to assume that the target population and its use of language are largely homogenous, and that the language system is more or less stable at a given point in time (Görlach, 1997:9). We therefore selected respondents aged 13 to 17 who most likely owned mobile phones and who were schooled in English as the language of instruction. We accordingly identified secondary schools, attended by learners with English first-language proficiency from the upper-middle class socioeconomic sphere.

Based on the overview of how textese is portrayed in the media and the point of saturation possibly already having been reached, we formulated the following null hypothesis:

SASSLATS will struggle to identify textisms in a formal writing context.

Concomitantly, our alternate hypothesis was formulated as follows:

SASSLATS will not struggle to identify textisms in a formal writing context.

Our alternate hypothesis was tested by means of a research instrument specifically designed to test whether SASSLATS would struggle to identify textisms in a formal writing context as defined above. 


\section{Research design and methodology}

\subsection{Research sites}

All the secondary schools selected as research sites excel academically and are consistently placed within the top 20 academic schools in the Pretoria region in terms of the number of distinctions achieved per learner, exit examination pass rates and university exemption i.e. delivering students eligible to apply for university admission based on minimum entry requirements. It was therefore assumed that these learners English writing and spelling abilities represented the upper end of the spectrum, with the assumption that schools that did not excel as well academically would probably have scored lower on the proofreading protocol.

We approached nine schools, five of which agreed to participate in the study. Of these five schools, four furnished us with completed instruments. Of these four schools, one school failed to request the learners and their parents to complete the letters of consent. The data obtained from this school were therefore inadmissible, meaning that three schools were ultimately used as research sites: two public schools and one private school. At the time of the study, the three research sites, henceforth labelled Site A, Site B and Site $\mathrm{C}$, had had $100 \%$ exit examination pass rates for several consecutive years, with one of the sites boasting a $100 \%$ exit examination pass rate since opening in 2007. In terms of learning resources, all three research sites had computer laboratories, low staff-tolearner ratios of approximately 1:25 and a wide variety of extramural activities ranging from bridge, business, and film clubs, to diverse sports such as angling, fencing and water polo. Given that the public schools were situated in a traditionally affluent, wellestablished part of the city, they were more akin to private schools in terms of the quality of education, school facilities and concomitant above-average school fees.

\subsection{Respondents}

Selection criteria for respondents were based on their age (between 13 and 17 years old), their grade (from grade 8 to 11), their being schooled in English and their comfortable socio-economic background. Respondents' gender was not a criterion for selection. All the respondents were enrolled at the type of school described in section 4.1. We argued that these respondents would be extremely likely to have their own mobile phones or at least ready access to one. Our assumption was reinforced by the fact that in 2013 already more than $75 \%$ of South Africans older than 15 years with an income of below R432 (approximately US\$40) per month per household member owned a mobile phone (Peyper 2013).

Based on public perceptions of the schools and after discussions with several educators, we assumed that the academic proficiency of, for example, a grade 10 learner in the selected private school would be similar to the academic proficiency of a grade 10 learner in the selected public schools. 


\subsection{Instrument design}

\subsubsection{Rationale}

Previous studies reported that actual textism use in writing samples produced by learners themselves is low because, unlike electronic devices, physical writing is not conducive to the use of certain textisms (Massey et al., 2005, Freudenberg, 2009). We therefore deemed it likely that written texts produced by SASSLATS would generally not contain particular textisms (such as emoticons) as they are difficult to replicate in physical writing. This influenced our decision not to use the written texts produced by our target group but rather design and administer a proofreading protocol (Addendum A). We compiled the proofreading protocol electronically in Microsoft Word, and printed it because, from a visual perspective, it resembled more closely the typed font produced by electronic devices. While we acknowledge that there are two different processes involved in writing and proofreading, we believed that a proofreading protocol was more likely to reveal whether SASSLATS have indeed reached the point of saturation and have become desensitised to identifying textisms in formal written English.

A further justification for using a proofreading protocol was that it would not 'cue' learners that there was a specific type of error, as a dictated or word recognition writing exercise would (a dictated spelling test requires learners to spell specific words correctly, thus they have to an extent been 'cued' as to what the 'error' is, while a word recognition exercise requires learners to identify the correct spelling of a word, thus also cuing them that only one option is correct). A proofreading protocol also allowed us to include target words as suggested by Drouin and Davis's (2009:65) study. These target words and features of textese are identified in the following section as categories of textese use.

\subsubsection{Categories of textese use and description of instrument}

Research by Plester et al. (2009), Drouin and Davis (2009) and Crystal (2008a) allowed us to classify textese use into the following categories:

1. shortenings, including omitted hyphenation;

2. contractions;

3. g-clippings;

4. other clippings;

5. omitted apostrophes;

6. omitted articles;

7. acronyms and initialisms;

8. symbols and emoticons; 

9. letter and number homophones;
10. non-conventional spellings;
11. informal tone and register;
12. lack of capitalisation; and
13. lack of punctuation.

Using the thirteen categories of textese use, we populated our proofreading protocol with four textese errors from each of the categories. There were thus 52 errors in the proofreading protocol, with the thirteen categories of textese use constituting the input variables. We emphasise that the objective of the study was not to investigate whether a direct causal relationship existed between textese (and the use thereof) and respondents' ability to identify textisms. We sought to establish whether or not the target population would struggle to identify textisms from the above-mentioned categories of textese as drawn from the relevant literature. We aimed to test whether respondents had become so desensitised to textisms, and on such a large scale, as suggested by the media. If this was indeed the case, we argued that respondents would struggle to identify textisms in formal written English.

In order to satisfy the criterion that the instrument should clearly contextualise the required use of language as formal (Omar \& Miah, 2012:13), we included a detailed brief for the learners, informing them that they were applying to Oxford University for a position. This contextualised the exercise as decidedly formal, meaning that any textisms would be inappropriate. We also phrased the instruction in such a manner so as not to cue the learners which errors they might find in the passage. No mention of textese was made, and the learners were merely requested to correct any errors that they might find.

\section{Data collection and analysis}

\subsection{Data collection procedure}

Although we had standardised ${ }^{2}$ our research instrument in terms of the marking rubric, time allocated, conditions under which they were completed, instructions and content, it had never been used in a study before. We conducted a pilot study at a different but comparative site to the research sites selected for the actual study. We requested five

2 For the purpose of our inquiry, 'standardised testing' shall be taken to denote the process of administering a test that is the same for all students in the testing population, taken under the same conditions and marked according to a commonly applied rubric (Matters, 2009:211). While our research instrument was thus standardised as per Matters' definition, I had not been used previously in any study. 
teachers to identify two learners in one of their classes to complete and comment on the learners' proofreading protocol. Comments received from the learners participating in the pilot study were encouraging as the instrument was completed accurately as per the task brief. The grade 10 and 11 learners completed the proofreading-type exercise slightly faster than the grade 8 and 9 learners. We had allowed 30 minutes for the completion which was deemed sufficient. In the actual study, all information sheets indicated that respondents had finished within the allotted time and that the matter of missing data was therefore not a factor that needed to be considered when interpreting the results.

We personally delivered the research instruments to the respective departmental heads of English at the participating sites in the first week of the third academic term in 2012 for distribution to the relevant English teachers. The detailed printed instructions were discussed with the heads of English prior to the research instruments being administered. While they did not invigilate the administration of the instrument, they took primary responsibility for distributing it to the English teachers whose classes were participating. Each grade's instruments and letters of consent were packaged in separate envelopes.

The English teachers administered the learners' proofreading protocol to one English class for each of the four grades involved in the study. As the same teacher was responsible for at least two classes, we could not stipulate that the instruments had to be administered during the same period. Although we had specifically requested the research sites to administer the learners' instruments during the third term of 2012, one school elected to administer the learners' proofreading protocol in January 2013. The feedback obtained from the information sheets completed by the teachers who administered the proofreading protocol revealed that nothing untoward had happened during the test sessions and that learners were generally intrigued by and willing to complete the proofreading protocol. The information sheets also confirmed that the learners had taken approximately 25 minutes to complete the instrument, which was consistent with the feedback obtained from the pilot study.

\subsection{Data analysis}

The responses provided by the learner respondents were captured on data-capturing sheets, which were subsequently verified against the original responses provided. For the purposes of categorising learners' responses as having either being 'overlooked' or 'corrected', all instances where learners failed to correct the textese error appropriately were marked as 'overlooked' as they might have marked 'corrections' on the instrument at random. The completed data sheets were then submitted for electronic capturing and statistical analysis. The electronically captured data were then once again verified against the original research instrument completed by the respondents to ensure that all the data had been captured correctly.

A statistical programming package (SAS) was used to obtain the data output. A summary of the results was included in the analysis, along with a breakdown of the mean and median scores achieved per grade, gender and research site, as well as the standard deviation (SD) for each variable. This summary is presented in Table 1. 
The data were captured and verified meticulously. However, we acknowledge that the natural situation in which the learners had completed the research instruments had necessarily been reduced as respondents were aware that completing the instrument was for research purposes and would not count towards their term mark, thus possibly influencing data validity.

\section{Results}

\subsection{Overview}

A total of 288 learner respondents $(n=288)$ completed the learners' proofreading protocol. Table 1 presents a breakdown of the number of respondents $(n)$ according to research site, the number of respondents per grade (from grade 8 to grade 11), and other information relating to gender, highest and lowest scores, the mean (average) score and the median score at the $50^{\text {th }}$ percentile (the score at which the same number of respondents achieved scores above and below the median) per research site, grade and gender. Expressed as percentages, the results represent a mean score of $63.5 \%$ $(n=288)$ and a median score of $65.4 \%(n=288)$ at the $50^{\text {th }}$ percentile on the learners' proofreading protocol. The close correlation between the mean and median scores (at the $50^{\text {th }}$ percentile) indicates that the results are not skewed towards either the better- or poorer-performing respondents.

The highest score attained was $94.2 \%$, with two learners achieving this score. In contrast, the lowest score was $21.2 \%$, with only one learner achieving this score. The results reveal that, on average, four out of five learners (83.3\%) scored more than $50 \%$ (thus denoting 'proficiency' within the context of this study), while only $16.7 \%$ of respondents scored less than $50 \%$ for the learners' proofreading protocol (thus denoting 'struggled' within the context of this study). A single difficulty indicator could also not be defined for all four target grades (grades 8 to 11) as it might be expected that the grade 11s would outperform the grade $8 \mathrm{~s}$. The research instrument could therefore have been perceived as being 'easy' or 'difficult', with varying perceptions across the four target grades (e.g. the grade 11s might have perceived the instrument as being 'easy' while it might have been more challenging for the grade 8s). However, as it had been designed to test a specific construct (namely to determine whether or not SASSLATS would identify textisms in formal written English), the difficulty rating of the instrument was relative and therefore deemed to be irrelevant as long as it tested what it was supposed to measure. Accordingly, the percentages give an indication of attainment, while the Student t-test and a significance level of either $1 \%(\alpha=0.01)$ or $5 \%(\alpha=0.05)$ were used to analyse the research hypothesis and test the statistical significance between different scores. 


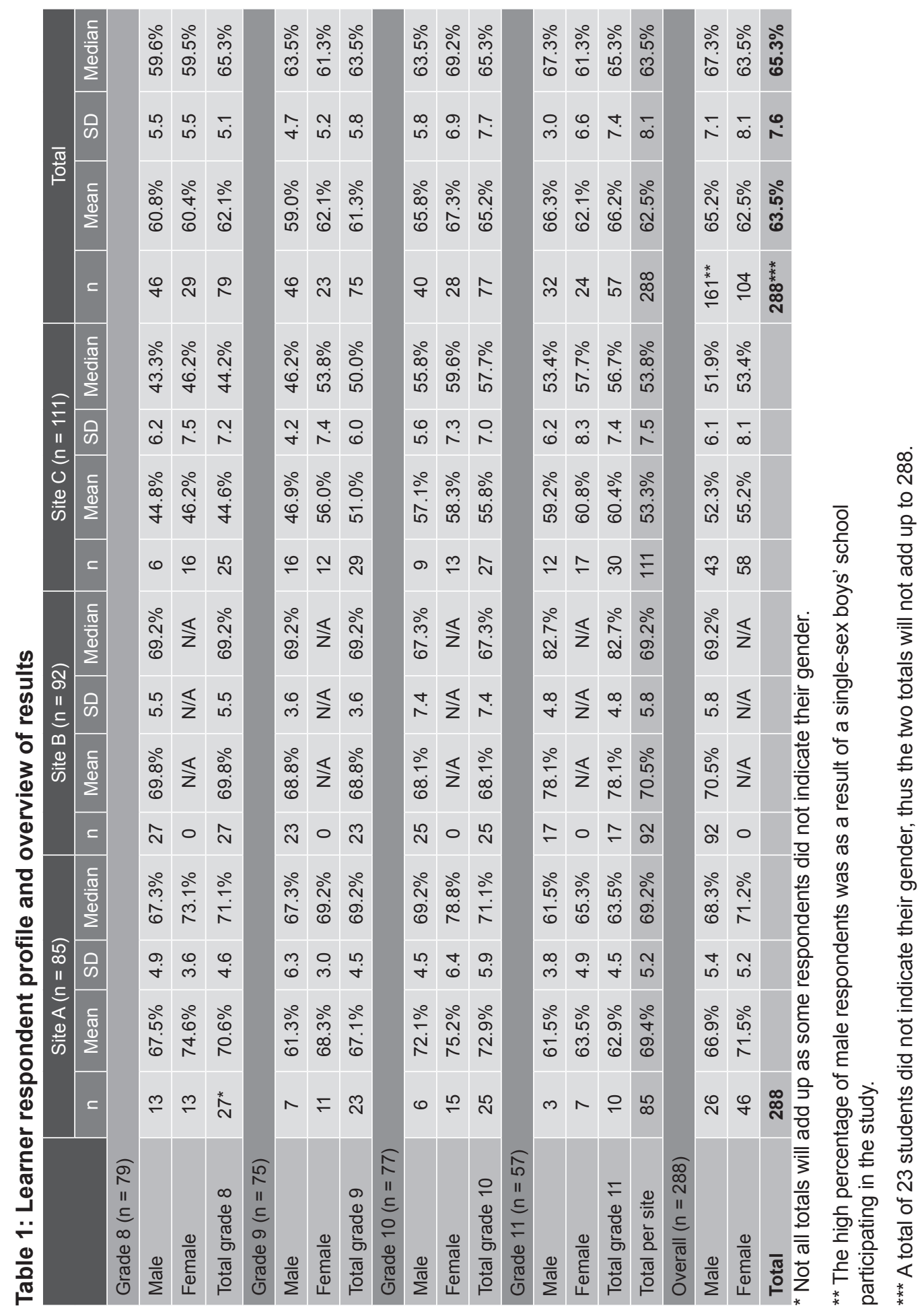


In addition to the mean (63.5\%) and median (65.3\%) scores achieved by the 288 respondents and the standard deviation of 7.6, the range - the difference between the highest (49 out of 52) and lowest (11 out of 52) scores - of 38 and the standard error of the mean of 0,45 indicate that there were no unexpected or significant outliers in the sample and point to a relatively normal data distribution for all 288 learner respondents. The closely correlating mean (63.5\%) and median (65.3\%) percentages further corroborate the normality of this data set. The data histogram for the 288 learner respondents is provided in the following figure.

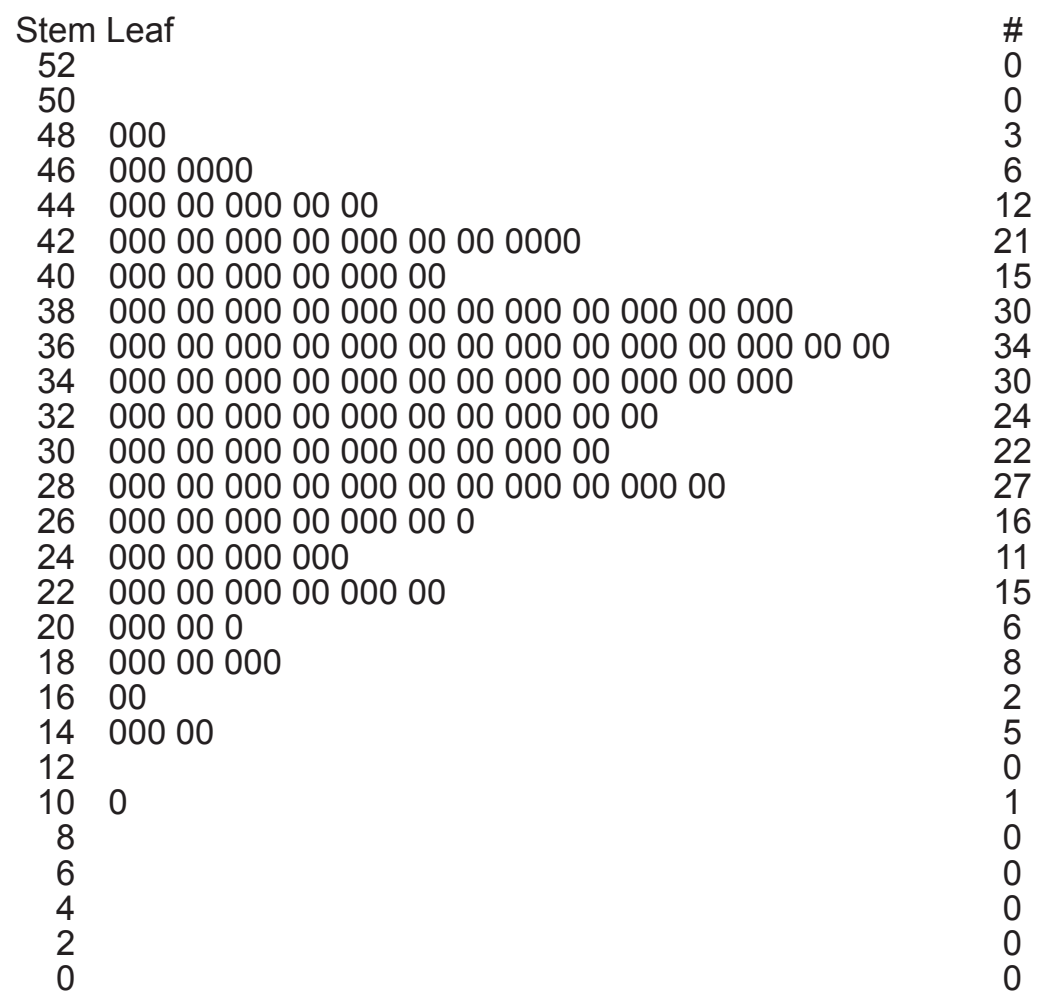

Figure 1: Data histogram: learner respondents 


\subsection{Testing of null hypothesis}

The descriptive statistics for all 288 learner respondents show a relatively standard distribution for our hypothesis test. Before testing our null hypothesis, it is reiterated that the proofreading protocol tested only the ability of SASSLATS to identify textisms in a formal writing context, and not their actual production of textisms in their own formal writing.

The normality of the distribution of the 288 learner respondents' responses allowed us to use the Student t-test to analyse our null hypothesis. The Student t-test resulted in a $p$-value of $p<0.0001$ and a t-statistic of 73.6. A significance level of $1 \%(\alpha=0.01)$ was used in order to be securely confident that the results were statistically significant. In order to obtain a result for our hypothesis test, we compared the $p$-value to the $\alpha(0.01)$. If the $p$-value is less than $\alpha$, then we could reject our null hypothesis that SASSLATS would struggle to identify textisms in a formal writing context, while if the p-value was not less than $\alpha$ then the null hypothesis could not be rejected (Gujarati \& Porter 2009: 128-138). Respondents were deemed to have 'struggled' to identify textisms in a formal writing context should they have failed to correct at least $50 \%$ of the textisms on the proofreading protocol. The mean score of $63.5 \%$ achieved by the 288 learner respondents was statistically significantly different from the $50 \%$ baseline measurement (denoting 'proficiency') at a 99\% confidence level $(p<0.01)$. We could therefore reject our null hypothesis as statistically SASSLATS do not struggle to identify textisms in a formal writing context.

The results show that SASSLATS possess sufficient metalinguistic knowledge: they thus have the ability to 'code-switch' and keep the conventions of textese and conventional English separate. The concern over textese as portrayed in the media is therefore unfounded as the results of this study strongly indicate that SASSLATS do have a precise grasp of register.

\subsection{Methodological limitations and further research}

The scope of our research was only to investigate SASSLATS' ability to identify textisms in formal written Standard English, so obtaining actual writing samples produced by learners would have allowed us to compare the 13 categories of textese use in terms of actual textese errors produced by the SASSLATS versus the textisms overlooked in our proofreading protocol. In retrospect we regret our decision not to sit in while the learner respondents completed the research instrument as this would have allowed us to observe first hand their reaction and attitude to completing the proofreading protocol possibly providing richer evidence. 
In terms of translating our results into implications for the classroom, no drastic intervention seems justified as existing interventions seem sufficiently robust to address textism use in SASSLATS' formal written English. Teachers should, however, continue to sensitise secondary school learners to the fact that different registers exist. Learners therefore should, on a continual basis, be reminded that while there are certain contexts where the use of textese is wholly appropriate, such as when communicating with friends, in online platforms and messaging applications such as WhatsApp, there are other contexts where a formal register might be required and where any use of textese would be inappropriate.

With regard to further avenues of potential research, it is recommended that the phenomenon of textese and secondary school learners' formal written English be investigated further by using a proofreading protocol (1) in other local and international contexts; (2) among different socio-economic classes, specifically among schools from the lower-income socio-economic sphere or rural areas whose learners would not necessarily have ready access to and use of mobile phones; (3) among secondlanguage English speakers; (4) among research sites less renowned for their academic attainment; and (5) among younger and older age groups, specifically primary school learners aged 10 to 12 (grades 5 to 7 ) and university students aged 18 to 21 (undergraduate students).

Complementing the use of a proofreading protocol by also focusing on the actual textisms produced by respondents when writing physically and typing electronically would be highly relevant. This finding concurs with Wood et al.'s (2014:99) recommendation on investigating the relationship between texting and the composition of formal connected text. Similarly, as Drouin and Davis (2009:63) found that it is unlikely that a decline in performance would be seen immediately and therefore recommended that the target population's performance on their research instrument should be tracked longitudinally. This limitation was also raised by Wood et al. (2014:33). Applying our protocol on the same target population at intervals of several years may produce interesting results. Such further inquiries will accordingly reveal whether future SASSLATS have become desensitised in respect of identifying textisms in formal written Standard English as a shortcoming of our inquiry was a benchmark against which we could compare our results.

\section{Conclusion}

The main contribution of our study has been the design and successful application of a valid proofreading protocol ${ }^{3}$ populated with relevant and plausible examples of actual textese use. To our knowledge, no previous study used this means of data collection to establish secondary school learners' ability to identify textisms in formal written Standard English. This study has shown that the negative portrayal of textese in the media is unfounded, as is the concern about the decay of English. SASSLATS do not

3 A Rasch analysis not discussed in this article was performed showing conclusively that the instrument was well targeted in relation to respondent ability and therefore able to provide reliable measures of the construct tested in this study. 
struggle to identify textisms in formal written Standard English, and they have a precise grasp of context as posited by Crystal (2008c), Thomas and McGee (2012:20), and Kasesniemi (2003:208). Our findings therefore support Wood et al.'s (2014:99) claim that it is unlikely text messaging will replace traditional literacy practices, and we too, see textese as "offering a new layer to language use rather than supplanting standard literacy conventions".

\section{References}

Associated Press. 2007. Irish government blames text messaging for teen illiteracy. Fox News.com. 26 April. http://www.foxnews.com/story/0,2933,268733,00. $\mathrm{html}$ ?sPage=fnc.technology/personaltechnology. Date of access: 17 September 2011.

Balakrishnan, V. \& Yeow, P.H.P. 2008. Text entry factors and texting satisfaction: An analysis among Malaysian users. Communications of the International Business Information Management Association 6(22): 191-197.

Barker, I. 2007. Txts $r$ gr8 but not in exams. Times Educational Supplement. 9 February. https://www.tes.co.uk/article.aspx?storycode=2341958. Date of access: 24 April 2012.

Bell, B. 2003. NC educators say instant messaging helps students write. The Charlotte Observer. 13 July. http://www.charlotte.com/mld/observer/news/local/6296395. $\mathrm{htm}$. Date of access: 17 September 2011.

Billington, J. 2008. In test, few students are proficient writers. Quoted in Dillon, S. The New York Times. April 3. http://www.nytimes.com/2008/04/03/education/03cndwriting.html?em\&ex $=1207454400 \&$ en $=a 866 a 90118 b 1 \mathrm{f3} 89 \& \mathrm{ei}=5087 \% 0 \mathrm{~A} \&$ r $=0$. Date of access: 3 March 2012.

Bodomo, A.B. 2009. Computer-Mediated Communication for Linguistics and Literacy: Technology and Natural Language Education. Hershey: Institute for Global Initiatives (IGI) Global.

Bolowana, A. 2005. R 2day's teens eroding English? Independent Online. 18 May. http://www.iol.co.za/news/south-africa/r-2day-s-teens-eroding-english-1.241471. Date of access: 31 July 2013.

Brown-Owens, A., Eason, M. \& Lader, A. 2003. What effect does computer-mediated communication, specifically Instant Messaging, have on 8th grade writing competencies? http://web.archive.org/web/20030821214021/http://www.usca. edu/medtech/courses/et780/may03/grouprojects/cmc-im.html. Date of access: 14 January 2012. 
Cable News Network. 2003. Text message essay baffles British teacher. 3 March. http://www.cnn.com/2003/EDUCATION/03/03/offbeat.text. essay.reut/. Date of access: 29 October 2011.

Campbell, J. 2008. Educators worry text messaging hurts student writing. Kentucky School Boards Association. 23 September. http://www.ksba.org/news/ article/ educators-worry-text-messaging-hurtsstudents-writing. Date of access: 16 June 2011.

Carrington, V. 2004. Txting: The end of civilization (again)? Cambridge Journal of Education 35(2): 161-175.

Cooke, H. 2012. SMS SOS! Text messages mark 20-year anniversary but have ALREADY been overtaken by Twitter and instant messaging. Daily Mail. 8 December. http://www. dailymail.co.uk/news/article-2241743/Text-messages-mark-20-year-anniversaryovertaken-Twitter-instant-messaging.html. Date of access: 2 January 2013.

Crace, J. 2008. Gr8 db8r takes on linguistic luddites. The Guardian. 16 September. http:// www.guardian.co.uk/education/2008/ sep/16/academicexperts.languages. Date of access: 15 November 2011.

Crystal, D. 2008a. Txtng: The Gr8 Db8. Oxford: Oxford University Press.

Crystal, D. 2008b. 2b or not 2b. The Guardian. 5 July. http://www.guardian.co.uk/books/2008/ jul/05/saturdayreviews featres.guardianreview. Date of access: 28 August 2011.

Crystal, D. 2008c. Interview with John Crace. Gr8 db8r takes on linguistic luddites. The Guardian. 16 September. http://www.guardian.co.uk/education/2008/sep/16/ academicexperts.languages. Date of access: 12 October 2012.

Drouin, M.A. \& Davis, C. 2009. R u txting? Is the use of text speak hurting your literacy? Journal of Literacy Research 41(1): 46-67.

Edwards, A. 2012. OMG! Txts make u gd at writing? Srsly? How 'text speak' can help pupils write essays. Daily Mail. 1 December. http://www.dailymail.co.uk/news/ article-2241325/OMG-Txts-make-u-gd-writing-Srsly-How-text-speak-help-pupilswrite-essays.html. Date of access: 1 June 2013.

Freudenberg, K. 2009. Investigating the Impact of SMS Speak on the Written Work of English First Language and English Second Language High School Learners. MA dissertation. Stellenbosch University.

Geertsema, S., Hyman, C. \& Van Deventer, C. 2011. Short message service (SMS) language and written skills: Educators' perspectives. South African Journal of Education 31(4): 475-487. 
Görlach, M. 1997. The Linguistic History of English. London: Macmillan.

Hamzah, M.S.B., Ghorbani, M.R. \& Abdullah, S.K.B. 2009. The impact of electronic communication technology on written language. US-China Education Review 6: 540-549.

Hård af Segerstad, Y. 2005. Language in SMS: A socio-linguistic view. In: Harper, R., Palen, L. \& Taylor, A. (Eds.) 2005. The Inside Text. Social, Cultural and Design Perspectives on SMS. Dordrecht: Kluwer Academic Publishers BV. pp. 33-51.

Humphrys, J. 2007. I h8 txt msgs: How texting is wrecking our language. Daily Mail. 24 September. http://www.daily mail.co.uk/news/article-483511/l-h8-txt-msgs-Howtexting-wrecking-language.html. Date of access: 3 January 2012.

Hyman, C. \& Van Deventer, C. 2009. Short Message Service (SMS) Language and Written Language Skills: Educators' Perspectives. Unpublished undergraduate mini-dissertation. University of Pretoria.

Jones, L. 2011. Ralph Fiennes blames Twitter for 'eroding' language. The Telegraph. 27 October. http://www.telegraph. co.uk/technology/twitter/8853427/RalphFiennes-blames-Twitter-for-eroding-language.html. Date of access: 8 February 2012.

Jumo, T. 2011. SMS spelling 'makes your child look stupid'. News 24. http://www.news24. com/Archives/Witness/SMS-spelling-makes-your-child-look-stupid-20150430. Date of access: 25 April 2015.

Kasesniemi, E. 2003. Mobile Messages: Young People and a New Communication Culture. Tempere, Finland: Tampere University Press.

Kemp, N. 2010. Texting versus txtng: reading and writing text messages, and links with other linguistic skills. Writing Systems Research 2(1): 53-71.

Lee, J. 2003. I Think, Therefore IM. New York Times. 19 April. http://www.nytimes. com/2002/09/19/technology/i-think-therefore-im.html?page wanted=1. Date of access: 16 June 2011.

Massey, A.J., Elliott, G.L. \& Johnson, N.K. 2005. Variations in aspects of writing in 16+ English examinations between 1980 and 2004: Vocabulary, spelling, punctuation, sentence structure, non-standard English. Research Matters: A Cambridge Assessment Publication, Special Issue. http://www.cambridgeassessment.org.uk/ ca/digitalAssets//113937_Variations_in_Aspects_of_Writing.pdf. Date of access: 27 February 2012. 
Matters, G.N. 2009. A problematic leap in the use of test data. From performance to inference. In: Wyatt Smith, C. \& Cummings, J. J. (Eds.) 2009. Educational Assessment in the 21 $1^{\text {st }}$ Century: Connecting Theory and Practice. New York: Springer Science and Business Media. pp. 209-225.

Nadeem, M., Mohsin, M.N. \& Ali, M.S. 2012. SMS: Short message service or sharp mutating service? Interdisciplinary Journal of Contemporary Research in Business 4(6): 1232-1248.

O'Connor, A. 2005. Instant messaging: Friend or foe of student writing? New Horizons for Learning. http://www.newhorizons.org/strategies/literacy/oconnor.htm. Date of access: 2 September 2011.

Omar, A. \& Miah, M. 2012. Impact of technology on teens' written language. International Journal of Advanced Trends in Computer Science and Engineering 1(1): 9-17.

Peyper, L. 2013. Mobile phone usage in SA. Finweek. 13 February. http://finweek. com/2013/01/22/mobile-phone-usage-in-sa/. Date of access: 6 December 2013.

Plester, B. \& Wood, C. 2009. Exploring relationships between traditional and new media literacies: British preteen texters at school. Journal of Computer-Mediated Communication 14: 1108-1129.

Plester, B., Wood, C. \& Joshi, P. 2009. Exploring the relationship between children's knowledge of text message abbreviations and school literacy outcomes. British Journal of Developmental Psychology 27: 145-161.

Prensky, M. 2001. Digital natives, digital immigrants. On the Horizon 9(5): 1-6.

Prigg, M. 2012. OMG: Researchers say text messaging really is leading to a generation with poor grammar skills. Daily Mail. 27 July. http://www.dailymail. co.uk/sciencetech/article-2179808/OMG-Researchers-say-text-messagingreally-leading-generation-poor-grammar-skills.html. Date of access: 10 March 2013.

Rankin, S.L. 2010. The Impact of Text Messaging Language Shortcuts on Developmental Students' Formal Writing Skills. Doctoral thesis, Walden University.

Sutherland, J. 2002. Can u txt? The Guardian. 11 November. http://www. guardian.co.uk/technology/2002/nov/11/mobile phones2. Date of access: 25 August 2011. 
Tagg, C., Baron, A. \& Rayson, P. 2012. i didn't spel that wrong did i. Oops: Analysis and normalisation of SMS spelling variation. Lingvisticæ Investigationes 35(2) 367-388.

The Pioneer. 2013. SMS, Internet texts are destroying English. 1 June. http://www. dailypioneer.com/state-editions/dehradun/sms-internet-texts-are-destroyingenglish.html. Date of access: 21 September 2014.

The Telegraph. 2012. Texting more popular than face-to-face conversation. 18 July. http://www.telegraph.co.uk/technology/ 9406420/Texting-more-popularthan-face-to-face-conversation.html. Date of access: 25 August 2012.

The Telegraph. 2012. Texting is fostering bad grammar and spelling, researchers claim. 27 July. http://www.telegraph.co. uk/education/ educationnews/9432222/Textingis-fostering-bad-grammar-and-spelling-researchers-claim.html. Date of access: 30 October 2012.

Thomas, D. 2012. How texting made history but ruined our language - and plenty of marriages. Daily Mail. 2 December. http://www.dailymail.co.uk/debate/ article-2241980/How-texting-history-ruined-language --plenty-marriages.html. Date of access: 1 May 2013.

Thomas, K.M. \& McGee, C.D. 2012. The only thing we have to fear is... 120 characters. TechTrends 56(1): 19-33.

Thurlow, C. 2006. From statistical panic to moral panic: The metadiscursive construction and popular exaggeration of new media language in the print media. Journal of Computer-Mediated Communication 11(3): 667-701.

Trask, R.L. 2000. The Dictionary of Historical and Comparative Linguistics. Edinburgh: Edinburgh University Press.

Uthus, E. 2007. Text messages destroying our language. The Daily. 7 May. http:// dailyuw.com/archive/2007/05/07/imported/text-messages-destroying-ourlanguage\#.UORhjW9kwow. Date of access: 24 May 2011.

Winzker, K., Southwood, F. \& Huddlestone, K. 2009. Investigating the impact of SMS speak on the written work of English first language and English second language high school learners. Per Linguam 25: 1-16.

Wood, C., Jackson, E., Hart, L., Plester, B. \& Wilde, L. 2011. The effect of text messaging on 9- and 10-year-old children's reading, spelling and phonological processing skills. Journal of Computer Assisted Learning 27: 28-36. 
Wood, C., Kemp, N. \& Plester, B. 2014. Text Messaging and Literacy - The Evidence. Florence, KY USA: Taylor \& Francis.

Wood, C., Kemp, N., Waldron, S. \& Hart, L. 2014. Grammatical understanding, literacy and text messaging in school children and undergraduate students: A concurrent analysis. Computers and Education 70: 281-290.

Wood, C., Meachem, S., Bowyer, S., Jackson, E., Tarczynski-Bowles, M.L. \& Plester, B. 2011. A longitudinal study of children's text messaging and literacy development. British Journal of Psychology 102: 431-442.

Wood, C., Plester, B. \& Bowyer, S. 2009. Liter8 Lrnrs: Is txting valuable or vandalism? British Academy Review, 14: 52-54.

\section{Addendum A: Learners' proofreading protocol}

[Front]

School:

Grade:

Gender: M / F (please

circle)

\section{Scenario}

You are applying for a job as the Head of Student Affairs at the University of Oxford in the United Kingdom. You have written the cover letter on the back of this page to accompany your curriculum vitae $(\mathrm{CV})$. Knowing that your application will be discarded immediately should the cover letter contain any errors, you read it one last time to ensure that you have corrected all the errors.

The letter on the back of this page might contain errors. Please correct all the errors that you find on the paper. Note that it is not necessary to rewrite any of the sentences. 


\title{
About the author
}

\author{
Herco Steyn \\ South African Reserve Bank \\ SARB Academy \\ 370 Helen Joseph Street \\ Pretoria, 0002
}

Email address: herco.steyn@resbank.co.za

\begin{abstract}
Herco Steyn holds a PhD in Humanities Education from the University of Pretoria and works as a learning and development consultant at the South African Reserve Bank Academy. His research interests include textese both within the educational environment and from a historical linguistics perspective.
\end{abstract}

\section{Rinelle Evans}

(corresponding author)

Faculty of Education

University of Pretoria

Pretoria 0002

South Africa

Email address: rinelle.evans@up.ac.za

Rinelle Evans is a rated researcher whose doctorate pertains to instructional communication via television technology. She is currently an associate professor involved with teacher education and facilitates modules related to literacies, communication skills and language-in-education issues. She also obtained a Masters degree in teaching English to speakers of other languages from the University of Birmingham, England and her academic interests thus relate to the methodology of English language teaching, and instructional design and communication. 